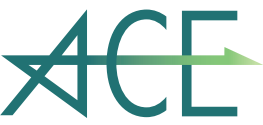

Annals of Clinical Epidemiology

ORIGINAL ARTICLE

\title{
Survival Benefits of Outpatient Cardiac Rehabilitation after Acute Myocardial Infarction: Propensity Analysis Using Japanese Administrative Database
}

\author{
Tomotsugu Seki ${ }^{1}$, Masato Takeuchi ${ }^{1}$, Shin Kawasoe ${ }^{1,2}$, Kazufumi Takeuchi $^{1}$, Ryusuke Miki ${ }^{1,3}$, \\ Kenji Ueshima ${ }^{4}$, Koji Kawakami ${ }^{1}$
}

\section{ABSTRACT}

BACKGROUND

Survival benefit of outpatient cardiac rehabilitation (CR) after acute myocardial infarction (AMI) has recently been contested under the current real-world clinical practice. We investigated whether outpatient CR was associated with lower mortality and morbidity risks among Japanese AMI patients.

\section{METHODS}

We analyzed patients who were admitted for AMI and received both percutaneous coronary intervention and inpatient CR from January 2011 to December 2014, using a nationwide administrative database in Japan (final date of follow-up: July 31, 2016). We compared patients who received outpatient CR and who did not, and the primary outcome was a composite of all-cause death and recurrence of AMI after the landmark time-point of day 180 after discharge. We applied Cox proportional hazards model to estimate outcomes, and propensity-score matching was applied to adjust for baseline imbalances.

RESULTS

A total of 5,654 patients (mean [SD] age, 66.8 [12.4] years; $21.2 \%$ female; median follow-up period [IQR] $1.44[0.87,2.27]$ years), 730 (12.9\%) participated in outpatient CR at least once within 180 days of discharge. Of 1,458 propensity-score matched patients, outpatient CR participation was associated with lower but statistically non-significant risks among the primary outcome ( 1.38 vs. 2.12 per 100 patient-years; $\mathrm{HR}=0.71 ; 95 \% \mathrm{CI}, 0.32$ to 1.61 ).

CONCLUSIONS

Among Japanese patients who admitted for AMI and received both percutaneous coronary intervention and inpatient CR, outpatient CR was underutilized, and associated with a statistically non-significant mortality and morbidity benefits. Further study is necessary to reaffirm the real-world effectiveness of outpatient CR under the current real-world clinical practice.

\section{KEY WORDS}

cardiac rehabilitation, myocardial infarction, coronary heart disease, medical record, mortality

\author{
1 Department of Pharmacoepidemiology, \\ Graduate School of Medicine and Public \\ Health, Kyoto University \\ 2 Department of Cardiovascular Medicine \\ and Hypertension, Graduate School of \\ Medical and Dental Sciences, Kagoshima \\ University \\ ${ }^{3}$ Health Policy Department, Health Divi- \\ sion, Health and Welfare Bureau \\ ${ }^{4}$ Center for Accessing Early Promising \\ Treatment, Kyoto University Hospital \\ Corresponding author: Koji Kawakami \\ Department of Pharmacoepidemiology, \\ Graduate School of Medicine and Public \\ Health, Kyoto University, Yoshida Konoe- \\ cho, Sakyo-ku, Kyoto, 606-8501 Japan \\ E-mail: kawakami.koji.4e@kyoto-u.ac.jp \\ Received: August 18, 2020 \\ Accepted: October 30, 2020 \\ No.21-03 \\ (c) 2021 Society for Clinical Epidemiology
}




\section{INTRODUCTION}

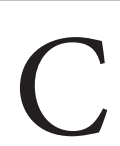

ardiac rehabilitation (CR) is a comprehensive lifestyle intervention that includes exercise training, risk-factor modification, education, stress management, and psychological support for patients with heart disease [1]. Systematic reviews of randomized control trials (RCTs) have reported that CR after acute myocardial infarction (AMI) reduce the risk of mortality and morbidities, and this intervention is widely recommended by the guidelines by The American College of Cardiology Foundation/The American Heart Association, The European Society of Cardiology, and The Japanese Circulation Society [2-5].

Recently, however, the survival benefit of CR has been questioned, because the abovementioned systematic reviews may have overestimated the effectiveness of $\mathrm{CR}$ due to publication bias, selective reporting featuring small trials, and large weights of the old studies before 1970s [6]. The Rehabilitation After Myocardial Infarction Trial (RAMIT), which evaluated the effectiveness of CR for 1,813 AMI patients in the UK, and recent systematic reviews showed non-significant or borderline benefits of CR on all-cause mortality [2, 7-9]. Furthermore, positive results of non-randomized studies in Western countries may not be generalizable to non-Western countries, because cardiac risk profiles and health-care environments are different, and previous studies in non-Western countries included too small sample sizes to evaluate the survival benefit [10-13].

Overall, the aim of the present study is to investigate, under current real-world clinical practice in a nonWestern country, whether outpatient CR participation is associated with a lower risk of mortality and morbidities than non-CR participation in patients who have been admitted for AMI and received percutaneous coronary intervention (PCI) and inpatient CR.

\section{METHODS}

\section{STUDY DESIGN AND DATA SOURCE}

This retrospective study was conducted using a nationwide administrative database provided by Medical Data Vision Co. Ltd. (Tokyo, Japan), which has been used for several clinical studies [14]. The database contains inpatient and outpatient administrative claims data and inpatient discharge abstracts for 16.0 million patients, sourced from 275 acute care hospitals with a Diagnosis Procedure Combination/Per Diem Payment System; this is similar to the Diagnosis Related Groups/Prospective
Payment System in the United States. The database well represent clinical practices in acute hospital and suitable for the study because patients with AMI is likely to admit to such acute care hospitals. The database includes the following data: anonymized patient identifiers; admission and discharge dates; primary and secondary diagnoses at admission, comorbidities at admission, and complications during admission (using International Classification of Diseases, 10th Revision [ICD-10] codes); devices, diagnostic tests, and therapeutic procedures (using Japanese procedural or claims codes); medications (using Anatomical Therapeutic Chemical [ATC] codes or Japanese claims codes); and number of hospital beds, stratified into three categories: below 200, 200 to 500, and over 500.

\section{PATIENT ELIGIBILITY CRITERIA}

We included patients who were admitted for AMI (ICD-10 code: I21.x) from January 2011 to December 2014, and who received PCI and inpatient CR during their hospitalization. Patients who did not receive inpatient CR were excluded, because 850 in 1535 (55.4\%) of certified teaching hospital by Japanese Circulation Society did not provide any CR program in 2014 [15]. Patients who did not receive inpatient CR was unlikely to receive outpatient $\mathrm{CR}$ under the circumstance. This restriction would improve the comparability of the patient and hospital characteristics due to the similarities in the indication of inpatient CR and facility criterion to provide inpatient CR. Following patients were also excluded: 1) who transferred to another hospital, discharged to a nursing home, or hospitalized for over 90 days during their initial hospitalization, because they were not likely to receive outpatient $\mathrm{CR}$ due to the high age, low ADL, severity of the AMI, various comorbidities and complications; 2) who experienced at least one of the following events during the initial hospitalization or within 180 days after discharge: all-cause death, readmission for AMI, or coronary artery bypass graft surgery; and 3) whose final visit after discharge was within 180 days of the initial hospitalization; 4) who received non-cardiac rehabilitation, because some patients in non-CR group might have received some rehabilitation (Fig. 1).

\section{EXPOSURE AND OUTCOME VARIABLES}

Patients were classified into two groups, a CR group and a non-CR group. Patients who received outpatient CR at least once within 180 days after discharge were classified into the CR group, while others were the non-CR group. We applied the period 180 days because CR, including both inpatient and outpatient, is covered 150 days in 


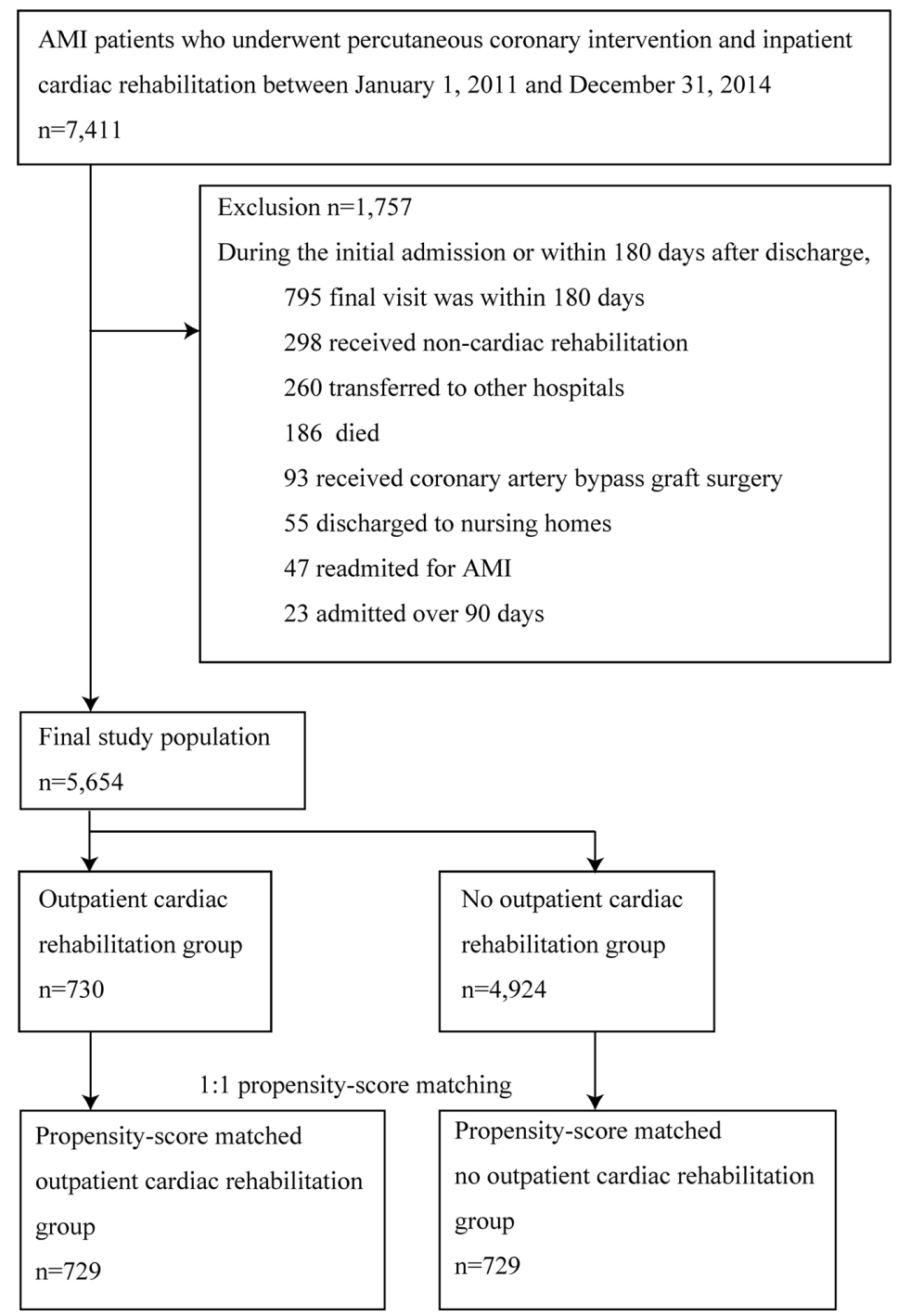

Fig. 1 Study flowchart. Flow diagram showing the process used to define the study population

AMI: Acute myocardial infarction; CR: cardiac rehabilitation; PS: propensity score.

Japanese health care system. Especially, outpatient CR is covered up to 60 min per session and 3 times a week. Patients were followed from the landmark time-point of 180 days after discharge until outcomes, the final visit, or July 31, 2016, whichever came first. The primary outcome was a composite of all-cause death or recurrence of AMI (whichever occurred first); and secondary outcomes were all-cause death, recurrence of AMI, and heart failure. These outcomes were detectable when they happened at the same hospital where the patient had admitted for the index AMI but not detectable if it happened at the different hospital.

\section{BASELINE VARIABLES}

These baseline variables were identified: patient characteristics including age, sex; body mass index, smoking history on admission; infarction site (anterior, inferior, or others) and Killip class (I, II, III or IV according to heart failure or cariogenic shock); ambulance use; activity of daily living (ADL) score at discharge (Barthel index, 100 or $<100$ ); length of initial hospitalization; comorbidities; procedures, devices, and prescriptions administered/used during the index admission; hospital characteristics, including the number of beds $(<500$ or $\geq 500)$ and teaching status (teaching or non-teaching; Supplemental Table 1). All comorbidities had been validated in Japanese administrative databases [16]. 


\section{ETHICAL CONSIDERATIONS}

The present study was approved by the ethics committee of Kyoto University Graduate School of Medicine (R1470). The requirement for informed consent was waived because all data were anonymized. This study followed the guidelines of the Strengthening the Reporting of Observational Studies in Epidemiology (STROBE), and The Reporting of studies Conducted using Observational Routinely-collected health Data (RECORD) Statements $[17,18]$.

\section{STATISTICAL ANALYSIS}

Categorical variables were presented as numbers and percentages. Continuous variables were presented as means and standard deviations if normally distributed, and as medians and interquartile range (IQR) otherwise. Survival analysis was conducted using the Kaplan-Meier method and log-rank tests, and Cox proportional hazards models were constructed to estimate the impact of outpatient CR on the primary and secondary outcomes. Results were expressed as HRs with 95\%CIs. Immortal time refers to a span of time in a follow-up period of a cohort during which the outcome under study could not have occurred because of exposure definition. For example, in the study, all patients in the CR group survived until their last CR session. To account for this bias, we conducted two types of analyses, landmark analysis as main analysis and Cox proportional hazards model with time-dependent variable as sensitivity analysis. [19, 20] We defined day 180 after discharge as "day 0," and conducted landmark analyses after this point. The proportional hazards assumption was assessed by the log-log survival curves to the log times and was found to be valid. We applied 1:1 propensity-score (PS) matching analysis to account for baseline imbalances observed between the $\mathrm{CR}$ and non-CR groups and to estimate unbiased treatment effects of outpatient CR. We used a logistic regression model for outpatient CR participation to calculate a PS for each patient in the study and included 41 baseline variables that we considered to be related to outcomes, regardless of the relation to CR participation (eAppendix in Supplement). We employed a greedy, nearest-neighbor matching algorithm with caliper widths of less than or equal to 0.2 of the standard deviation of the logit of the PS without replacement to form pairs of patients who received and did not receive outpatient CR. The balance between the $\mathrm{CR}$ and non-CR groups was assessed using absolute standardized differences, and we defined a standardized difference greater than 0.1 as a meaningful covariate imbalance between the groups before and after PS matching [21]. As we observed a significant imbalance in some covariates between patients who had at least one missing variable and those who did not, it was not plausible that the assumptions were missing completely at random (Supplemental Table 2). Consequently, we employed multiple imputation methods using a chained equation to create 20 datasets, which would mitigate potential bias as a result of missing data, under the assumption that the data were missing at random rather than missing not at random [22]. The imputation models included all covariates for the primary analysis and outcomes. After multiple-imputing the missing covariates data and calculating PSs, we averaged each patient's 20 PSs, matching the outpatient CR group and non-outpatient CR group based on their averaged scores and estimating the treatment effects [23]. We conducted subgroup analyses to evaluate statistical interactions between outpatient CR and clinically relevant subgroups; these groups were based on variables including age, sex, infarction site, Killip class, and low-ADL at discharge. Furthermore, we conducted sensitivity analyses to check the consistency of the results in the primary analysis and the extent of the biases. First, we conducted 1:2 and 1:3 PS matching, and inverse probability of treatment weighting method (average treatment effect on treatment) to account for the loss of sample size in the nonCR group as a result of 1:1 matching. Next, to account for immortal time bias, we constructed a Cox proportional hazards model with a time-dependent variable but without the 180-day landmark period. A time-dependent variable was defined as the period from the discharge to the last outpatient CR session, which accounted for immortal time bias. The immortal time was moved from the CR group to the non-CR group. Additionally, we conducted several sensitivity analyses. First, we compared patients within the CR group whose period between the first and last outpatient CR was longer than or equal to 90 days (the median period of outpatient CR) and short-CR participants. Second, we compared patients who received outpatient CR once a week or more frequent (the median frequency of outpatient CR) and less-frequent (less than once a week) participants. Third, we compared patients whose total number of outpatient session was more than 7 (the median number of outpatient CR) and equal or fewer than 7. We considered two-sided p-values of <.05 to be statistically significant. All analyses were conducted using SAS version 9.4 (SAS Institute). 
RESULTS

\section{BASELINE CHARACTERISTICS}

A total of 7,411 patients were admitted for AMI and received both PCI and inpatient CR between January 2011 and December 2014. After applying the exclusion criteria, 1,757 patients were excluded, and the final study population comprised 5,654 patients, with a median (IQR) follow-up period of 1.44 years $(0.87,2.27$; Fig. 1). Patients in the CR group were younger, had a higher body mass index, were more likely to have anterior AMI, diabetes, and were more likely to be prescribed statins and oral anticoagulants, but were less likely to have peripheral vascular disease, renal disease, and low-ADL. More patients in the CR group were admitted to hospitals with $<500$ beds (Table 1). After multiple imputation and 1:1 PS matching, 729 pairs were created, without significant differences regarding baseline characteristics, between the CR and non-CR groups (Table $\mathbf{1}$ and Supplemental Tables 3-5).

\section{OUTPATIENT CR PARTICIPATION}

Among the final study population, 730 (12.9\%) received at least one outpatient CR session within 180 days after discharge. During the study period, the percentage of CR participants increased from $8.1 \%$ in 2011 to $13.9 \%$ in 2014. Among the CR group, the median (IQR) period from discharge to the first outpatient CR was nine $(4,17)$ days; the median (IQR) period between the first and the last CR was $93.5(14,145)$ days; the median (IQR) number of the CR session was $7(2,16) ; 404$ (55.3\%) patients received outpatient CR less than once a week, 288 (39.5\%) received once a week, and 38 (5.2\%) patients received twice or more per week.

\section{OUTCOMES}

In crude analysis, incidence rates of the primary composite outcome of all-cause death and AMI between the CR and non-CR groups were 1.38 and 2.57 per 100 patientyears, respectively, and we observed a significantly low risk in the $\mathrm{CR}$ group regarding the primary outcome (HR $=0.51 ; 95 \% \mathrm{CI}, 0.31$ to $0.83 ; \mathrm{p}=.007)$. In contrast, in the matched cohort, incidence rates of the primary composite outcome of all-cause death and AMI between the CR and non-CR groups were 1.38 and 2.12 per 100 patientyears, respectively. We did not observe any significant difference between the $\mathrm{CR}$ and non-CR groups regarding the primary outcome $(\mathrm{HR}=0.71 ; 95 \% \mathrm{CI}, 0.32$ to 1.61 ; $P=.42$; Fig. 2). Further, between the $\mathrm{CR}$ and non-CR groups all secondary outcomes were also not significantly different (Table 2).

\section{SUBGROUP AND SENSITIVITY ANALYSES}

In subgroup analyses, no statistical interaction was observed among relevant subgroups. Similarly, we observed no significant differences among 1:2, 1:3 PS matching analyses, inverse probability treatment weighting, and the Cox proportional hazards model with a time-dependent variable. On the other hand, the relationship between duration, frequency, and the total number of outpatient CR and subsequent outcomes were not consistent among analyses (Fig. 3).

\section{DISCUSSION}

In this retrospective study examined patients with AMI who received both PCI and inpatient CR, 12.9\% of the patients received at least one outpatient CR. However, among 1,458 propensity-score matched patients, statistically non-significant survival benefit of outpatient CR was observed.

Recently, the survival benefit of CR has been questioned, because recent randomized evidence have shown that CR may have non-significant or borderline effects regarding all-cause and cardiovascular mortalities $[5,6$, 9]. In the updated Cochrane review in 2016, CR did not decrease all-cause mortality contrary to a previous version in 2011, whereas cardiovascular mortality was decreased in both reviews; this discrepancy was attributed to two reasons [2]. First, publication bias and selective reporting with small studies were suspected in these systematic reviews $[6,24]$. For instance, the RAMIT trial, which examined 1,813 AMI patients in the UK found no survival benefit of $\mathrm{CR}$ regarding all-cause mortality at one, two, or 7-9 years [7]. We assume that the change in the 2016 update was largely influenced by the findings of the RAMIT, because the overall median sample size of included studies in the systematic review was only 126 [7]. Second, some older trials in the 1960s and 1970s attributed large weights in these systematic reviews [25, 26]. In one study, $20 \%$ and $30 \%$ of patients in the CR and non-CR groups died after a three-year follow-up [25]. Mortality risk in these old studies was substantially higher because none of coronary care units, primary PCI, and current evidence-based drugs were available. To account for this problem, Powell et al. included only patients who were recruited after 2000 in their review, and no benefit of CR was observed regarding all-cause and cardiovascular mortality [9]. Consistent results both in the present study and recent randomized evidence 


\begin{tabular}{|c|c|c|c|c|c|c|}
\hline & \multicolumn{3}{|c|}{ Before matching } & \multicolumn{3}{|c|}{ After matching } \\
\hline & $\begin{array}{l}\text { CR group, } \\
\mathrm{n}=730\end{array}$ & $\begin{array}{c}\text { Non-CR group, } \\
\mathrm{n}=4,924\end{array}$ & $\mathrm{SD}, \%$ & $\begin{array}{l}\text { CR group, } \\
\mathrm{n}=729\end{array}$ & $\begin{array}{c}\text { Non-CR group, } \\
\mathrm{n}=729\end{array}$ & $\mathrm{SD}, \%$ \\
\hline \multicolumn{7}{|l|}{ Patient characteristics } \\
\hline Age, years, mean (SD) & $65.1(11.0)$ & $67.0(12.5)$ & 16 & $65.1(11.0)$ & $65.0(12.4)$ & 1.3 \\
\hline Male sex, n (\%) & $589(80.7)$ & $3,865(78.5)$ & 5.4 & $588(80.7)$ & $567(77.8)$ & 7.1 \\
\hline Body mass index, mean (SD) & $24.4(3.7)$ & $23.9(3.7)$ & 13 & $24.4(3.7)$ & $24.4(4.0)$ & 0.7 \\
\hline Body mass index, missing, $\mathrm{n}(\%)$ & $35(4.8)$ & $315(6.4)$ & 7 & $35(4.8)$ & $48(6.6)$ & 7.7 \\
\hline Smoking history, n (\%) & $336(55.8)$ & $2,555(58.9)$ & 6.3 & $336(55.9)$ & $346(54.2)$ & 3.4 \\
\hline Smoking history, missing, n (\%) & $128(17.5)$ & $589(12.0)$ & 16 & $128(17.6)$ & $91(12.5)$ & 14 \\
\hline Killip class, n (\%) & & & & . & . & \\
\hline 1 & $384(54.5)$ & $2,591(55.1)$ & 1.3 & $384(54.5)$ & $354(50.6)$ & 7.8 \\
\hline 2 & $222(31.5)$ & $1,419(30.2)$ & 2.9 & $221(31.4)$ & $252(36.1)$ & 9.9 \\
\hline 3 & $48(6.8)$ & $351(7.5)$ & 2.5 & $48(6.8)$ & $44(6.3)$ & 2.1 \\
\hline 4 & $51(7.2)$ & $342(7.3)$ & 0.1 & $51(7.2)$ & $49(7.0)$ & 0.9 \\
\hline Killip class, missing, n (\%) & $25(3.4)$ & $221(4.5)$ & 5.5 & $25(3.4)$ & $30(4.1)$ & 3.6 \\
\hline Infarction site & & & & . & . & \\
\hline Anterior, n (\%) & $334(45.8)$ & $2,010(40.8)$ & 10 & $333(45.7)$ & $335(46.0)$ & 0.6 \\
\hline Inferior, n (\%) & $247(33.8)$ & $1,646(33.4)$ & 0.9 & $247(33.9)$ & $232(31.8)$ & 4.4 \\
\hline Other, n (\%) & $67(9.2)$ & $546(11.1)$ & 6.3 & $67(9.2)$ & $80(11.0)$ & 5.9 \\
\hline Infarction site, missing, $\mathrm{n}(\%)$ & $66(9.0)$ & $532(10.8)$ & 5.9 & $66(9.1)$ & $79(10.8)$ & 6 \\
\hline Ambulance use, n (\%) & $425(58.2)$ & $3,036(61.7)$ & 7 & $425(58.3)$ & $406(55.7)$ & 5.3 \\
\hline Ambulance use, missing, $\mathrm{n}(\%)$ & $0(0.0)$ & $1(0.0)$ & NA & & & \\
\hline Low-ADL at discharge, $\mathrm{n}(\%)$ & $34(4.7)$ & $726(14.8)$ & 35 & $34(4.7)$ & $33(4.6)$ & 0.6 \\
\hline ADL at discharge, missing, $\mathrm{n}(\%)$ & $3(0.4)$ & $20(0.4)$ & 0.1 & $3(0.4)$ & $4(0.5)$ & 2 \\
\hline Length of admission, days, median (IQR) & $14(11,20)$ & $14(11,19)$ & 2.1 & $16.7(9.4)$ & $16.8(8.9)$ & 1 \\
\hline Comorbidities & & & & . & . & \\
\hline Peripheral vascular disease, $\mathrm{n}(\%)$ & $43(5.9)$ & $435(8.8)$ & 11 & $43(5.9)$ & $40(5.5)$ & 1.8 \\
\hline Cerebral artery disease, $\mathrm{n}(\%)$ & $33(4.5)$ & $318(6.5)$ & 8.5 & $33(4.5)$ & $42(5.8)$ & 5.6 \\
\hline Chronic pulmonary disease, $\mathrm{n}(\%)$ & $26(3.6)$ & $195(4.0)$ & 2.1 & $26(3.6)$ & $20(2.7)$ & 4.7 \\
\hline Liver disease, $\mathrm{n}(\%)$ & $23(3.2)$ & $131(2.7)$ & 2.9 & $23(3.2)$ & $23(3.2)$ & 0 \\
\hline Diabetes mellitus, n (\%) & $264(36.2)$ & $1,445(29.3)$ & 15 & $263(36.1)$ & $255(35.0)$ & 2.3 \\
\hline Renal disease, $\mathrm{n}(\%)$ & $16(2.2)$ & $235(4.8)$ & 14 & $16(2.2)$ & $19(2.6)$ & 2.7 \\
\hline Malignant neoplasms, n (\%) & $18(2.5)$ & $163(3.3)$ & 5 & $18(2.5)$ & $16(2.2)$ & 1.8 \\
\hline Procedures and devices & & & & . & . & \\
\hline Drug-eluting stent use, n (\%) & $498(68.2)$ & $3,238(65.8)$ & 5.2 & $498(68.3)$ & $495(67.9)$ & 0.9 \\
\hline Bare-metal stent use, $\mathrm{n}(\%)$ & $234(32.1)$ & $1,774(36.0)$ & 8.4 & $234(32.1)$ & $230(31.6)$ & 1.2 \\
\hline $\begin{array}{l}\text { Values are presented as means (SDs) if normally } \\
\text { Body mass index was calculated as weight in kil } \\
\text { Abbreviations: SD, standard difference; ACE, a } \\
\text { unit; CR, cardiac rehabilitation; IABP, intra-aor }\end{array}$ & $\begin{array}{l}\text { median (IQR) } \\
\text { d by the squar } \\
\text { nverting enzy } \\
\text { mping; ICU, ir }\end{array}$ & $\begin{array}{l}\text { normally distrib } \\
\text { ight in meters. } \\
\text { DL, activities of } \\
\text { e care unit. }\end{array}$ & $\begin{array}{l}\text { or nun } \\
\text { living; }\end{array}$ & $\begin{array}{l}\text { riables, and } \\
\text { giotensin re }\end{array}$ & $\begin{array}{l}\text { f categorical var } \\
\text { blockers; CCU, }\end{array}$ & ry care \\
\hline
\end{tabular}




\begin{tabular}{|c|c|c|c|c|c|c|}
\hline \multirow{2}{*}{ Table 1-2 Baseline characteristics } & \multicolumn{3}{|c|}{ Before matching } & \multicolumn{3}{|c|}{ After matching } \\
\hline & $\begin{array}{l}\text { CR group, } \\
\mathrm{n}=730\end{array}$ & $\begin{array}{c}\text { Non-CR group, } \\
\mathrm{n}=4,924\end{array}$ & $\mathrm{SD}, \%$ & $\begin{array}{c}\text { CR group, } \\
\text { n }=729\end{array}$ & $\begin{array}{c}\text { Non-CR group, } \\
n=729\end{array}$ & $\mathrm{SD}, \%$ \\
\hline \multicolumn{4}{|l|}{ Number of coronary stents, n (\%) } & \multicolumn{3}{|c|}{. } \\
\hline 1 & $370(50.7)$ & $2,623(53.3)$ & 5.2 & $370(50.8)$ & $396(54.3)$ & 7.1 \\
\hline 2 & $155(21.2)$ & $1,133(23.0)$ & 4.3 & $155(21.3)$ & $143(19.6)$ & 4.1 \\
\hline 3 & $70(9.6)$ & $527(10.7)$ & 3.7 & $70(9.6)$ & $63(8.6)$ & 3.3 \\
\hline$\geq 4$ & $76(10.4)$ & $390(7.9)$ & 8.6 & $76(10.4)$ & $84(11.5)$ & 3.5 \\
\hline ICU/CCU admission, $\mathrm{n}(\%)$ & $629(86.2)$ & $4,189(85.1)$ & 3.1 & $629(86.3)$ & $631(86.6)$ & 0.8 \\
\hline Respirator, n (\%) & $68(9.3)$ & $344(7.0)$ & 8.5 & $67(9.2)$ & $65(8.9)$ & 1 \\
\hline Hemodialysis, n (\%) & $11(1.5)$ & $112(2.3)$ & 5.6 & $11(1.5)$ & $8(1.1)$ & 3.6 \\
\hline IABP, n (\%) & $109(14.9)$ & $604(12.3)$ & 7.8 & $108(14.8)$ & $109(15.0)$ & 0.4 \\
\hline Transfusion, $\mathrm{n}(\%)$ & $24(3.3)$ & $253(5.1)$ & 9.2 & $24(3.3)$ & $21(2.9)$ & 2.4 \\
\hline \multicolumn{4}{|l|}{ Medications } & \multicolumn{3}{|c|}{. } \\
\hline Aspirin, n (\%) & $720(98.6)$ & $4,859(98.7)$ & 0.4 & $719(98.6)$ & $718(98.5)$ & 1.2 \\
\hline P2Y12 inhibitors, n (\%) & $715(97.9)$ & $4,821(97.9)$ & 0.3 & $714(97.9)$ & $707(97.0)$ & 6.1 \\
\hline Oral anticoagulants, $\mathrm{n}(\%)$ & $123(16.8)$ & $615(12.5)$ & 12 & $122(16.7)$ & $127(17.4)$ & 1.8 \\
\hline ACE inhibitors/ARBs, n (\%) & $594(81.4)$ & $3,911(79.4)$ & 4.9 & $593(81.3)$ & $609(83.5)$ & 5.8 \\
\hline Beta blockers, n (\%) & $526(72.1)$ & $3,435(69.8)$ & 5.1 & $525(72.0)$ & $527(72.3)$ & 0.6 \\
\hline Statins, n (\%) & $664(91.0)$ & $4,327(87.9)$ & 10 & $663(90.9)$ & $655(89.8)$ & 3.7 \\
\hline Catecholamines, n (\%) & $187(25.6)$ & $1,126(22.9)$ & 6.4 & $186(25.5)$ & $190(26.1)$ & 1.3 \\
\hline \multicolumn{4}{|l|}{ Hospital characteristics } & \multicolumn{3}{|c|}{. } \\
\hline Number of beds, $\geq 500, \mathrm{n}(\%)$ & $231(31.6)$ & $2,110(42.9)$ & 23 & $498(68.3)$ & $475(65.2)$ & 6.7 \\
\hline Teaching hospital, n (\%) & $654(89.6)$ & $4,350(88.3)$ & 4 & $231(31.7)$ & $254(34.8)$ & 6.7 \\
\hline \multicolumn{3}{|l|}{ Calendar year } & & $653(89.6)$ & $660(90.5)$ & 3.2 \\
\hline $2011, \mathrm{n}(\%)$ & $52(6.7)$ & $537(10.5)$ & 13 & \multicolumn{3}{|c|}{ - } \\
\hline $2012, \mathrm{n}(\%)$ & $88(11.3)$ & $737(14.3)$ & 9.1 & $52(7.1)$ & $54(7.4)$ & 1.1 \\
\hline $2013, \mathrm{n}(\%)$ & $231(29.7)$ & $1,431(27.9)$ & 4.1 & $88(12.1)$ & $88(12.1)$ & 0 \\
\hline $2014, \mathrm{n}(\%)$ & $359(46.1)$ & $2,219(43.2)$ & 5.9 & $230(31.6)$ & $227(31.1)$ & 0.9 \\
\hline \multicolumn{7}{|c|}{$\begin{array}{l}\text { Values are presented as means (SDs) if normally distributed, median (IQR) if non-normally distributed for numerical variables, and N (\%) if categorical variables. } \\
\text { Body mass index was calculated as weight in kilograms divided by the square of height in meters. } \\
\text { Abbreviations: SD, standard difference; ACE, angiotensin-converting enzyme; ADL, activities of daily living; ARB, angiotensin receptor blockers; CCU, coronary care } \\
\text { unit; CR, cardiac rehabilitation; IABP, intra-aortic balloon pumping; ICU, intensive care unit. }\end{array}$} \\
\hline
\end{tabular}

insist that CR might have no survival benefits under the current evidence-based clinical practice.

On the other hand, results in the present study were inconsistent with non-randomized studies that had reported lower mortality risks for CR participants [12, 27]. For example, the Cardiac Rehabilitation Outcome Study, which systematically reviewed 46,338 patients after acute coronary syndrome, showed significant lower mortality risks both in prospective and retrospective cohort studies [12]. We assumed the following reasons for the discrepancy. First, the sample size of 1,458 in the present study may have been insufficient to detect the survival benefit of $\mathrm{CR}$, whereas some non-randomized studies in Western countries included more than 10,000 patients $[24,25]$. It was somewhat owing to insufficient CR delivery and uptake in Japan, because the outpatient 


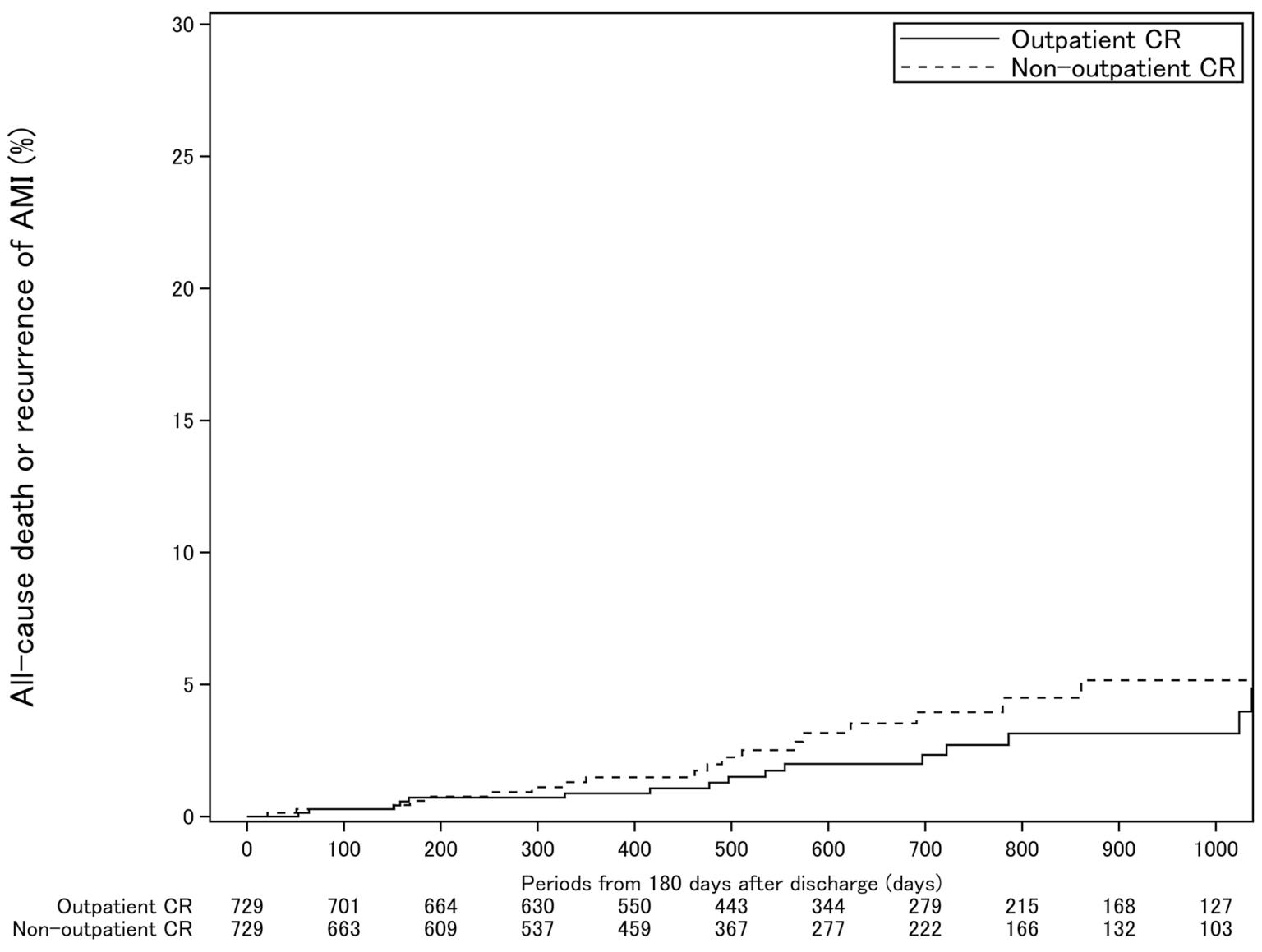

Fig. 2 Kaplan-Meier cumulative event curve with and without outpatient cardiac rehabilitation in the propensity-score matched cohort

This figure shows the Kaplan-Meier cumulative event curve for multiple imputed and 1:1 propensity-score matched patients $(\mathrm{n}=1,458)$, including those who received outpatient cardiac rehabilitation (CR group, $n=729$ ) and those who did not (non-CR group, $n=729$ ), on the composite of allcause death and/or recurrence of acute myocardial infarction. AMI: acute myocardial infarction; CR: cardiac rehabilitation.

Table 2 Primary and secondary outcomes in 1:1 propensity score matching analysis

\begin{tabular}{|c|c|c|c|c|c|c|}
\hline & \multicolumn{2}{|c|}{ CR group $(n=729)$} & \multicolumn{2}{|c|}{ Non-CR group $(\mathrm{n}=729)$} & \multirow{2}{*}{ HR $(95 \% \mathrm{CI})$} & \multirow{2}{*}{$P$ value ${ }^{\mathrm{a}}$} \\
\hline & No. of events & Incidence rate ${ }^{\mathrm{b}}$ & No. of events & Incidence rate ${ }^{b}$ & & \\
\hline All-cause death and/or recurrence of AMI & 18 & 1.38 & 24 & 2.12 & $0.71(0.32$ to 1.61$)$ & 0.42 \\
\hline All-cause death & 9 & 0.68 & 15 & 1.31 & $0.83(0.25$ to 2.73$)$ & 0.76 \\
\hline Recurrence of AMI & 9 & 0.69 & 10 & 0.88 & $0.56(0.19$ to 1.66$)$ & 0.29 \\
\hline Heart failure & 26 & 2.01 & 23 & 2.06 & 0.89 (0.47 to 1.72$)$ & 0.74 \\
\hline
\end{tabular}

Outcomes were analyzed for a multiple imputed and 1:1 propensity score matched cohort $(\mathrm{n}=1,458)$ of 5,654 total patients. Data were analyzed using the Cox proportional hazards model, and the landmark day 180 after discharge from the index admission was defined as day 0 in the analysis. A HR $<1$ favors outpatient CR participation.

Abbreviations: AMI, acute myocardial infarction; CR, cardiac rehabilitation.

${ }^{\text {a }} \mathrm{P}$ values for log-rank test

${ }^{\mathrm{b}}$ Incidence rates are shown as no. of cases per 100 patient-year 
Subgroup \& Sensitivity No. (\%) of Analyses Patients
Hazard Ratio

$(95 \% \mathrm{CI})$

Subgroup analysis

Overall (1:1 match)

Age

$<66$

$1458(100)$

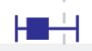

$0.64(0.35-1.17)$

$66-75$

$703(48.2)$

$465(31.8)$

$>75$

$290(19.8)$

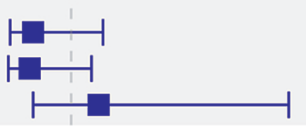

Sex

Male

$1155(79.2)$

Female

$303(20.7)$

Smoking history

Smoking

$682(46.7)$

Non-smoking

557 (38.2)

Killip class

I

738 (50.6)

II-IV

665 (45.6)

Infarction site

Anterior

Non-anterior

$668(45.8)$

645 (44.2)

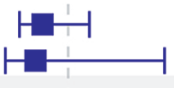

$0.42(0.14-1.27)$

$1.37(0.48-3.97)$

Diabetes

Yes

518 (35.5)

No

940 (64.4)

Low ADL

Yes

$67(4.6)$

No

$1384(95.4)$

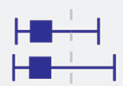

$0.65(0.33-1.28)$

$0.55(0.13-2.32)$

$0.58(0.25-1.37)$

$0.58(0.21-1.59)$

$1.19(0.42-3.36)$

$0.49(0.21-1.16)$

$0.96(0.37-2.50)$

$0.46(0.18-1.18)$
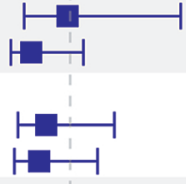

$0.68(0.29-1.60)$

$0.57(0.24-1.38)$

Sensitivity analyses

$\begin{array}{lr}\text { 1:2 match } & 2183 \\ \text { 1:3 match } & 2893 \\ \text { IPTW (ATT) } & 5654 \\ \text { Time-dependent analysis } & 1490 \\ \text { Duration of CR } & 729 \\ \text { Frequency of CR } & 729 \\ \text { Number of CR } & 729\end{array}$

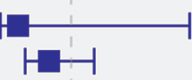

$0.27(0.03-2.62)$

$0.69(0.36-1.31)$

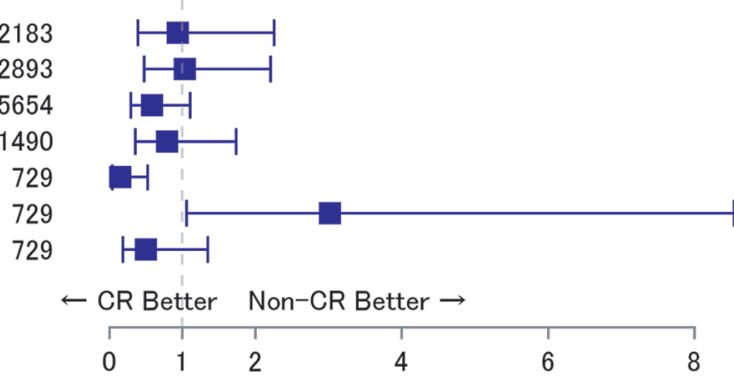

$0.94(0.39-2.25)$

$1.03(0.48-2.21)$

$0.58(0.30-1.10) \quad 0.09$

$0.79(0.36-1.73) \quad 0.55$

$0.15(0.04-0.53) \quad 0.003$

3.01 (1.06-8.54) 0.04

$0.50(0.18-1.35) \quad 0.17$

Fig. 3 Forest plot of subgroup and sensitivity analyses

Subgroup analyses were conducted for the multiple imputed and 1:1 propensity score matched cohort $(\mathrm{n}=1,458)$ on the primary composite outcome of all-cause death and recurrence of acute myocardial infarction. The sum of group totals of nos. and percentages regarding smoking history, Killip class, infarction site, and low activity of daily living do not add to $100 \%$ because groups of missing data are not shown. $P$ values were calculated for the interaction between outpatient cardiac rehabilitation (CR) and each subgroup in subgroup analyses. Duration of CR compared long-CR (patients whose period between their first and last CR session was longer than or equal to 90 days) with short-CR being attributed otherwise. Frequency of CR compared patients who received outpatient CR once a week or more frequent and less than once a week. Number of CR compared patients whose total number of outpatient CR was more than 7 and equal or less than 7.

ADL: activity of daily living; CR: cardiac rehabilitation; IPTW: inverse probability of treatment weighting; ATT: average treatment effect on treatment.

CR participants is much fewer than in Western countries (i.e., $13 \%$ vs. $30 \%)[24,26]$. It is possible that the low CR intensity concealed the benefit of CR, because $95 \%$ of the CR participants received outpatient CR once or less per week in the present study, although Japanese guideline recommended the exercise at least three times a week [3]. Second, in the present study, the mortality rate of 1.0 per
100 patient-years was approximately one-fifth of what is observed in Western countries [27, 28]. Even if outpatient CR has some survival benefit, it would be relatively difficult to detect the benefit in some low-risk populations such as those from East Asia, because of their low cardiovascular risk [13].

Among sensitivity analyses, we observed a significantly 
lower risk for patients who continued outpatient CR over 90 days than for those who did not. Similar doseresponse associations have also been shown in some observational studies [30, 31]. The result insists that higher dose of outpatient CR may be associated with better prognosis. However, other sensitivity analyses showed non-significant or high risks if the patient received outpatient $\mathrm{CR}$ more frequently or who received more outpatient $\mathrm{CR}$ session. As a result, the doseresponse association between outpatient CR participation and the outcome is also still unclear.

There are some strength in the present study. First, the study is the largest study other than the North America and Europe. Because most study about CR derived from such Western countries, the generalizability in nonWestern country, especially in Asia, is still uncertain. Therefore, generalizability of our results in Asian country must be high. Second, our results was consistent among various sensitivity analyses and it support the consistency of our analyses. In contrast, there are several limitations in the present study. First, because this study was not an RCT, it is impossible to draw any conclusions regarding causation because of confounding. In addition, our data did not include some important patient characteristics (e.g., left ventricular ejection fraction, severity of coronary artery disease, and socio-economic status), because the data were originally collected for billing purposes. Second, as noted above, statistically non-significant results in the present study can have been caused by beta error due to the insufficient statistical power (e.g., limited sample size, lower CR uptake, and short follow-up period), even though we applied multiple imputation methods to mitigate the loss of sample size and bias due to missing data [22]. For example, the median follow-up period of 1.5 years in the present study may have been too short to detect the benefits of CR [12]. Third, the primary and secondary outcomes may be underestimated because the MDV database does not include any information other than contract institutions, and linkage to other databases including National Death Index was impossible. Fourth, type, dose, and intensity of exercise and quality of CR programs were undetectable in the present study, whereas all institutions were authorized by local bureaus of health and welfare for reimbursement. Since some performance measures and quality indicators of CR have been proposed, quality evaluation and assurance should be undergone in future studies [32]. Fifth, the results of the present study should not be applied to other indications such as post-cardiac surgery, stable coronary artery disease, and heart failure. Similarly, the present study's results should be generalized with caution, as they may not fully represent different risk populations or health-care environments.

\section{CONCLUSION}

Among Japanese patients who admitted for AMI and received both percutaneous coronary intervention and inpatient CR, outpatient CR was underutilized, and associated with a statistically non-significant mortality and morbidity benefits. Real-world effectiveness of outpatient CR should be reaffirmed under the current real-world clinical practice.

\section{ACKNOWLEDGMENT}

We would like to thank Mr. Masaki Nakamura, Medical Data Vision Co., Ltd., for the provision of the data.

The authors disclosed receipt of the following financial support for the research, authorship, and/or publication of this article: This research was supported by JSPS KAKENHI [Grant Number JP19K10509].

\section{DECLARATION OF CONFLICTING INTERESTS}

KK received honoraria from Astellas, Eisai, Abbie, Takeda Pharmaceutical Company Limited, Novartis KK, Santen, Bayer Yakuhin, Sanofi K.K., Kyowa Hakko Kirin, and Otsuka Pharmaceutical, and consultation fees from Olympus and Kaken Pharmaceutical. There are no patents, products in development, or marketed products to declare relevant to those companies. All other authors report that they have no relationships to disclose that are relevant to the contents of this paper.

\section{AUTHORS' CONTRIBUTIONS}

TS, MT, SK, KT and RM contributed to concept or design of the study. TS, MT and KK contributed the acquisition or analysis. TS, MT, SK, KT, RM and KU contributed interpretation of the data. TS drafted the manuscript and all authors critically revised the manuscript. All authors gave final approval and agree the be accountable for all aspects of the work ensuring integrity and accuracy.

REFERENCES

1. Dalal HM, Doherty P, Taylor RS. Cardiac rehabilitation. BMJ 2015;351:h5000.
2. Anderson L, Thompson DR, Oldridge N, Zwisler AD, Rees K, Martin N, et al. Exercise- based cardiac rehabilitation for coronary heart disease. The Cochrane Database of Syst 
Rev 2016:Cd001800.

3. O'Gara PT, Kushner FG, Ascheim DD, Casey DE, Jr, Chung MK, de Lemos JA, et al. 2013 ACCF/AHA guideline for the management of ST-elevation myocardial infarction: a report of the American College of Cardiology Foundation/American Heart Association Task Force on Practice Guidelines. J Am Coll Cardiol 2013;61:e78-140.

4. Ibanez B, James S, Agewall S, Antunes MJ, Bucciarelli-Ducci C, Bueno H, et al. 2017 ESC Guidelines for the management of acute myocardial infarction in patients presenting with ST-segment elevationThe Task Force for the management of acute myocardial infarction in patients presenting with ST-segment elevation of the European Society of Cardiology (ESC). Eur Heart J 2017;39(2):119-77.

5. Guidelines for rehabilitation in patients with cardiovascular disease (JCS 2012). Circ J 2014;78:2022-93.

6. West R, Jones D. Cardiac rehabilitation and mortality reduction after myocardial infarction: the emperor's new clothes? Evidence against cardiac rehabilitation. Heart 2013;99: 911-3.

7. West RR, Jones DA, Henderson AH. Rehabilitation after myocardial infarction trial (RAMIT): multi-centre randomised controlled trial of comprehensive cardiac rehabilitation in patients following acute myocardial infarction. Heart 2012;98:637-44.

8. van Halewijn G, Deckers J, Tay HY, van Domburg R, Kotseva K, Wood D. Lessons from contemporary trials of cardiovascular prevention and rehabilitation: A systematic review and meta-analysis. Int $J$ Cardiol 2017;232:294-303.

9. Powell R, McGregor G, Ennis S, Kimani $\mathrm{PK}$, Underwood M. Is exercise-based cardiac rehabilitation effective? A systematic review and meta-analysis to re-examine the evidence. BMJ Open 2018;8:e019656.

10. Seki E, Watanabe $Y$, Shimada $K$, Sunayama S, Onishi T, Kawakami K, et al. Effects of a phase III cardiac rehabilitation program on physical status and lipid profiles in elderly patients with coronary artery disease: Juntendo Cardiac Rehabilitation Program (J-CARP). Circ J 2008;72:1230-4.

11. Lee HY, Kim JH, Kim BO, Byun YS, Cho $\mathrm{S}$, Goh CW, et al. Regular exercise training reduces coronary restenosis after percutaneous coronary intervention in patients with acute myocardial infarction. Int J Cardiol
2013;167:2617-22.

12. Rauch B, Davos CH, Doherty P, Saure D, Metzendorf MI, Salzwedel A, et al. The prognostic effect of cardiac rehabilitation in the era of acute revascularisation and statin therapy: A systematic review and meta-analysis of randomized and non-randomized studiesThe Cardiac Rehabilitation Outcome Study (CROS). Eur J Prev Cardiol 2016;23:1914-39. 13. Ueshima H, Sekikawa A, Miura K, Turin TC, Takashima N, Kita Y, et al. Cardiovascular disease and risk factors in Asia: a selected review. Circulation 2008;118:2702-9.

14. Seki T, Takeuchi M, Miki R, Kawakami K. Follow-up tests and outcomes for patients undergoing percutaneous coronary intervention: analysis of a Japanese administrative database. Heart Vessels 2019;34:33-43.

15. The Japanese Registry Of All cardiac and vascular Diseases (JROAD) Annual Report 2014. Available from: http://www.j-circ.or.jp/ jittai_chosa/jittai_chosa2014web.pdf, Accessed 2020 Sep 15 (in Japanese)

16. Yamana $H$, Moriwaki $M$, Horiguchi $H$, Kodan M, Fushimi K, Yasunaga H. Validity of diagnoses, procedures, and laboratory data in Japanese administrative data. J Epidemiol 2017;27:476-82.

17. von Elm E, Altman DG, Egger M, Pocock SJ, Gotzsche PC, Vandenbroucke JP. The Strengthening the Reporting of Observational Studies in Epidemiology (STROBE) statement: guidelines for reporting observational studies. Ann Intern Med 2007;147:573-7.

18. Benchimol EI, Smeeth L, Guttmann A, Harron K, Moher D, Petersen I, et al. The REporting of studies Conducted using Observational Routinely-collected health Data (RECORD) statement. PLoS Med 2015;12: e1001885.

19. Levesque LE, Hanley JA, Kezouh A, Suissa S. Problem of immortal time bias in cohort studies: example using statins for preventing progression of diabetes. BMJ 2010;340:b5087.

20. Mi X, Hammill BG, Curtis LH, Lai EC-C, Setoguchi S. Use of the landmark method to address immortal person-time bias in comparative effectiveness research: a simulation study. Stat Med 2016;35:4824-36.

21. Austin PC. An Introduction to propensity score methods for reducing the effects of confounding in observational studies. Multivariate Behav Res 2011;46:399-424.

22. Sterne JA, White IR, Carlin JB, Spratt M,
Royston P, Kenward MG, et al. Multiple imputation for missing data in epidemiological and clinical research: potential and pitfalls. BMJ 2009;338:b2393.

23. Mitra R, Reiter JP. A comparison of two methods of estimating propensity scores after multiple imputation. Stat Methods Med Res 2016;25:188-204.

24. Sterne JA, Egger M, Smith GD. Systematic reviews in health care: Investigating and dealing with publication and other biases in meta-analysis. BMJ 2001;323:101-5.

25. Kallio V, Hämäläinen H, Hakkila J, Luurila $\mathrm{O}$. Reduction in sudden deaths by a multifactorial intervention programme after acute myocardial infarction. The Lancet 1979;314:1091-4. 26. Dorn J, Naughton J, Imamura D, Trevisan M. Results of a multicenter randomized clinical trial of exercise and long-term survival in myocardial infarction patients: the National Exercise and Heart Disease Project (NEHDP). Circulation 1999;100:1764-9.

27. de Vries H, Kemps HM, van EngenVerheul MM, Kraaijenhagen RA, Peek N. Cardiac rehabilitation and survival in a large representative community cohort of Dutch patients. Eur Heart J 2015;36:1519-28.

28. Suaya JA, Stason WB, Ades PA, Normand SL, Shepard DS. Cardiac rehabilitation and survival in older coronary patients. J Am Coll Cardiol 2009;54:25-33.

29. Kanazawa N, Ueshima K, Tominari S, Nakayama T. Underuse of cardiac rehabilitation in workers with coronary artery diseaseClaims database survey in Japan. Circ J 2017;81:1424-31.

30. Martin BJ, Hauer T, Arena R, Austford LD, Galbraith PD, Lewin AM, et al. Cardiac rehabilitation attendance and outcomes in coronary artery disease patients. Circulation 2012;126:677-87.

31. Hammill BG, Curtis LH, Schulman KA, Whellan DJ. Relationship between cardiac rehabilitation and long-term risks of death and myocardial infarction among elderly medicare beneficiaries. Circulation 2010;121:63-70.

32. Thomas RJ, Balady G, Banka G, Beckie TM, Chiu J, Gokak S, et al. 2018 ACC/AHA clinical performance and quality measures for cardiac rehabilitation. A report of the American College of Cardiology/American Heart Association Task Force On Performance Measures. J Am Coll Cardiol 2018:24587. 
eAppendix List of covariates for estimating propensity score

- Patient characteristics: Age, sex, body mass index, smoking history, Killip class (1-4), infarction site (anterior, inferior, other), ambulance use, and low-ADL at discharge

- Comorbidities: Peripheral vascular disease, cerebral artery disease, chronic pulmonary disease, liver disease, diabetes mellitus, renal disease, and malignant neoplasms

- Procedural characteristics: Drug-eluting stent use, bare-metal stent use, number of coronary stents $(1,2,3, \geq 4)$, intensive care unit/coronary care unit admission, respirator use, hemodialysis, intra-aortic balloon pump use, or transfusion

- Medication: Aspirin, P2Y12 inhibitors, oral anticoagulants, ACE inhibitors/ARBs, beta blockers, statins, catecholamines

- Calendar years: 2011 to 2014

Abbreviations: ADL, activity of dairy living; $\mathrm{ACE}$, angiotensin converting enzyme; ARB, angiotensin receptor blockers 


\begin{tabular}{|c|c|}
\hline Diagnosis & ICD-10 codes \\
\hline AMI & I21.x \\
\hline Anterior wall & I21.0 \\
\hline Inferior wall & I21.1 \\
\hline Other sites & $\mathrm{I} 21.2$ \\
\hline Peripheral vascular disease & I70.x, I71.x, I73.1, I73.8, I73.9, I77.1, I79.0, I79.2, K55.1, K55.8, K55.9, Z95.8, Z95.9 \\
\hline Cerebrovascular disease & G45.x, G46.x, H34.0, I60.x-69.x \\
\hline Chronic pulmonary disease & I27.8, I27.9, J40.x-47.x, J60.x-67.x, J68.4, J70.1, J70.3 \\
\hline Liver disease & $\begin{array}{l}\text { B18.x, I85.0, I85.9, I86.4, I98.2, K70.0 - 70.4, K70.9, K71.1, K71.3-71.5, K71.7, K72.1, K72.9, } \\
\text { K73.x, K74.x, K76.0, K76.2-76.9, Z94.4 }\end{array}$ \\
\hline Diabetes & E10.x-14.x \\
\hline Renal disease & I12.0, I13.1, N03.2-N03.7, N05.2-N05.7, N18.x, N19.x, N25.0, Z49.0-Z49.2, Z94.0, Z99.2 \\
\hline Malignant neoplasms & $\begin{array}{l}\text { C00.x-C26.x, C30.x-C34.x, C37.x-C41.x, C43.x, C45.x-C58.x, C60.x-C85.x, C88.x, C90.x- } \\
\text { C97.x }\end{array}$ \\
\hline Procedures & Japanese procedural codes or claims codes \\
\hline Percutaneous coronary intervention & K546.x-550.x \\
\hline Coronary artery bypass grafting & K552.x \\
\hline Cardiac rehabilitation & H000.1, H000.2 \\
\hline Non-cardiac rehabilitation & H001.x, H002.x, H003.x \\
\hline Intensive care unit/Coronary care unit admission & A300.x, A301.x \\
\hline Respirator & J045.x \\
\hline Hemodialysis & J038.x \\
\hline Blood transfusion & K920.x \\
\hline Intra-aortic balloon pumping & K600.x \\
\hline Drug-eluting stent & 710010026 \\
\hline Bare-metal stent & 710010018 \\
\hline Teaching hospital & A204.2 \\
\hline Medications & ATC codes or claims codes \\
\hline Aspirin & B01C1, B01C5, B01C9 \\
\hline P2Y12 inhibitors & $\mathrm{B} 01 \mathrm{C} 2, \mathrm{~B} 01 \mathrm{C} 5$ \\
\hline Oral anti-coagulants & B01A0, B01E0, B01F0 \\
\hline ACE inhibitors/ARBs & C09A, C09C, C09D \\
\hline Beta blockers & $\mathrm{C} 07$ \\
\hline Statins & $\mathrm{C} 10 \mathrm{~A} 1, \mathrm{C} 11 \mathrm{~A} 1$ \\
\hline Catecholamines & $620008384,642450071,642450165$ \\
\hline Outcomes & ICD-10 codes \\
\hline Recurrence of AMI & I21.x, I22.x \\
\hline Heart failure & I50.x \\
\hline
\end{tabular}


Supplemental Table 2 Baseline characteristics, with and without missing variables

Missing variable $(+) n=1,643 \quad$ Missing variable $(-) n=4,011 \quad$ Standardized difference, $\%$

Clinical characteristics

Age, years, mean (SD)

Male sex, $\mathrm{n}(\%)$

$\begin{array}{lll}66.5(12.3) & 66.9(12.4) & 3.4\end{array}$

Body mass index, mean (SD)

$1,285(78.2)$

3,169

$24.0(3.6)$

$24.0(3.8)$

$532(57.5)$

$2,359(58.8)$

1.9

Killip class, $\mathrm{n}(\%)$

2

3

4

Infarction site

Anterior, n (\%)

$818(58.6)$

375 (26.8)

2,157 (53.8)

95 (6.8)

1,266 (31.6)

$109(7.8)$

304 (7.6)

284 (7.1)

2.8

Inferior, n (\%)

451 (27.4)

$341(20.8)$

Other, n (\%)

603 (36.7)

996 (60.7)

215 (13.3)

Low-ADL at discharge, $\mathrm{n}(\%)$

$16.9(10.2)$

Comorbidities

Peripheral vascular disease, $\mathrm{n}(\%)$

Cerebral artery disease, $\mathrm{n}(\%)$

$134(8.2)$

$100(6.1)$

$1,893(47.2)$

$1,552(38.7)$

$10(0.2)$

2,465 (61.5)

$545(13.6)$

$16.4(9.1)$

Chronic pulmonary disease, $\mathrm{n}(\%)$

$69(4.2)$

57 (3.5)

Liver disease, $\mathrm{n}(\%)$

Diabetes mellitus, $\mathrm{n}(\%)$

$553(33.7)$

79 (4.8)

48 (2.9)

344 (8.6)

$251(6.3)$

152 (3.8)

$97(2.4)$

$1,156(28.8)$

$172(4.3)$

Malignant neoplasms, n (\%)

Procedural characteristics

Drug-eluting stent, $\mathrm{n}(\%)$

$1,132(68.9)$

133 (3.3)

9.6

10

3

2.8

Bare-metal stent, $\mathrm{n}(\%)$

$500(30.4)$

2,604 (64.9)

1,508 (37.6)

42

Number of coronary stents, $\mathrm{n}$ (\%)

2

3

$\geq 4$

ICU/CCU admission, n (\%)

864 (52.6)

$2,129(53.1)$

357 (21.7)

195 (11.9)

$931(23.2)$

$119(7.2)$

$402(10.0)$

$1,429(87.0)$

347 (8.7)

Respirator use, $\mathrm{n}(\%)$

$141(8.6)$

$33(2.0)$

$3,389(84.5)$

Hemodialysis, $\mathrm{n}(\%)$

$230(14.0)$

$271(6.8)$

$90(2.2)$

$483(12.0)$

Transfusion, $\mathrm{n}(\%)$

96 (5.8)

$181(4.5)$

Medications

Aspirin, $\mathrm{n}(\%)$

P2Y12 inhibitors, $\mathrm{n}(\%)$

$1,621(98.7)$

,958 (98.7)

3,933 (98.1)

,603 (97.6)

$185(11.3)$

$553(13.8)$

3,275 (81.7)

ACE inhibitors/ARBs, $\mathrm{n}(\%)$

$1,230(74.9)$

$2,816(70.2)$

145 (69.7)

3,569 (89.0)

364 (22.2)

949 (23.7)

Catecholamine, $\mathrm{n}$ (\%)

$811(49.4)$

$1530(38.1)$

$1,488(90.6)$

$3,516(87.7)$

40
106

1.6

0.9

5.5

characteristics

Teaching hospital, n (\%)

$156(9.5)$

$221(13.5)$

$493(30.0)$

433 (10.8)

1.5

0.7

2.1

6.2

10

2.5

2.3

2011, n (\%)

773 (47.0)

$604(15.1)$

$1,169(29.1)$

2013, n (\%)

1,805 (45.0)

8.5

15

2014, n (\%)

A patient was classified into the missing variable $(+)$ group if the patient had at least one missing value.

Values are presented as means (SDs) if normally distributed, median (IQR) if non-normally distributed numerical variables, and N (\%) if categorical variables.

Body mass index was calculated as weight in kilograms divided by the square of height in meters.

Abbreviations: CR, cardiac rehabilitation; SD, standard deviation; IQR, interquartile range; ADL, activities of daily living; ICU, intensive care unit;

$\mathrm{CCU}$, coronary care unit; IABP, intra-aortic balloon pumping; ACE, angiotensin-converting enzyme; ARB, angiotensin receptor blockers. 
Supplemental Table 3 Baseline characteristics of the imputed and matched cohort (1/20)

\begin{tabular}{|c|c|c|c|}
\hline & CR group, $\mathrm{n}=727$ & No CR group, $\mathrm{n}=727$ & Standardized difference, $\%$ \\
\hline \multicolumn{4}{|l|}{ Clinical characteristics } \\
\hline Age, years, mean (SD) & $65.1(11.0)$ & $65.3(12.3)$ & 1.9 \\
\hline Male sex, n (\%) & $586(80.6)$ & $580(79.8)$ & 2.1 \\
\hline Body mass index, mean (SD) & $24.4(3.7)$ & $24.1(3.6)$ & 8.2 \\
\hline Smoking history, n (\%) & $414(56.9)$ & $409(56.3)$ & 1.4 \\
\hline \multicolumn{4}{|l|}{ Killip class, n (\%) } \\
\hline 1 & $395(54.3)$ & $382(52.5)$ & 3.6 \\
\hline 2 & $227(31.2)$ & $234(32.2)$ & 2.1 \\
\hline 3 & $50(6.9)$ & $51(7.0)$ & 0.5 \\
\hline 4 & $55(7.6)$ & $60(8.3)$ & 2.5 \\
\hline \multicolumn{4}{|l|}{ Infarction site } \\
\hline Anterior, n (\%) & $356(49.0)$ & $345(47.5)$ & 3 \\
\hline Inferior, $\mathrm{n}(\%)$ & $274(37.7)$ & $279(38.4)$ & 1.4 \\
\hline Other, n (\%) & $97(13.3)$ & $103(14.2)$ & 2.4 \\
\hline Ambulance use, $\mathrm{n}(\%)$ & $425(58.5)$ & $424(58.3)$ & 0.3 \\
\hline \multicolumn{4}{|l|}{ Comorbidities } \\
\hline Peripheral vascular disease, $\mathrm{n}(\%)$ & $43(5.9)$ & $33(4.5)$ & 6.2 \\
\hline Cerebral artery disease, $\mathrm{n}(\%)$ & $33(4.5)$ & $29(4.0)$ & 2.7 \\
\hline Chronic pulmonary disease, $\mathrm{n}(\%)$ & $25(3.4)$ & $35(4.8)$ & 6.9 \\
\hline Liver disease, $\mathrm{n}(\%)$ & $23(3.2)$ & $24(3.3)$ & 0.8 \\
\hline Diabetes mellitus, n (\%) & $261(35.9)$ & $262(36.0)$ & 0.3 \\
\hline Renal disease, n (\%) & $16(2.2)$ & $13(1.8)$ & 3 \\
\hline Malignant neoplasms, n (\%) & $18(2.5)$ & $12(1.7)$ & 5.8 \\
\hline Low-ADL at discharge, $\mathrm{n}(\%)$ & $36(5.0)$ & $40(5.5)$ & 2.5 \\
\hline \multicolumn{4}{|l|}{ Procedural characteristics } \\
\hline Drug-eluting stent, n (\%) & $496(68.2)$ & $489(67.3)$ & 2.1 \\
\hline Bare-metal stent, n (\%) & $234(32.2)$ & $243(33.4)$ & 2.6 \\
\hline \multicolumn{4}{|l|}{ Number of coronary stents, n (\%) } \\
\hline 1 & $369(50.8)$ & $387(53.2)$ & 5 \\
\hline 2 & $155(21.3)$ & $163(22.4)$ & 2.7 \\
\hline 3 & $70(9.6)$ & $59(8.1)$ & 5.3 \\
\hline$\geq 4$ & $75(10.3)$ & $81(11.1)$ & 2.7 \\
\hline ICU/CCU admission, n (\%) & $627(86.2)$ & $630(86.7)$ & 1.2 \\
\hline Respirator use, $\mathrm{n}(\%)$ & $65(8.9)$ & $67(9.2)$ & 1 \\
\hline Hemodialysis, n (\%) & $11(1.5)$ & $10(1.4)$ & 1.2 \\
\hline IABP use, n (\%) & $106(14.6)$ & $120(16.5)$ & 5.3 \\
\hline Transfusion, $\mathrm{n}(\%)$ & $24(3.3)$ & $22(3.0)$ & 1.6 \\
\hline Admission period, days, mean (SD) & $16.6(9.0)$ & $16.8(9.6)$ & 2.4 \\
\hline \multicolumn{4}{|l|}{ Medications } \\
\hline Aspirin, n (\%) & $717(98.6)$ & $717(98.6)$ & 0 \\
\hline P2Y12 inhibitors, n (\%) & $712(97.9)$ & $715(98.3)$ & 3.1 \\
\hline Oral anticoagulants, n (\%) & $121(16.6)$ & $113(15.5)$ & 3 \\
\hline ACE inhibitors/ARBs, n (\%) & $591(81.3)$ & $577(79.4)$ & 4.8 \\
\hline Beta blockers, n (\%) & $523(71.9)$ & $540(74.3)$ & 5.3 \\
\hline Statins, n (\%) & $661(90.9)$ & $666(91.6)$ & 2.4 \\
\hline Catecholamine, $\mathrm{n}(\%)$ & $184(25.3)$ & $178(24.5)$ & 1.9 \\
\hline \multicolumn{4}{|l|}{ Hospital characteristics } \\
\hline Number of beds, $\geq 500, \mathrm{n}(\%)$ & $231(31.8)$ & $247(34.0)$ & 4.7 \\
\hline Teaching hospital, n (\%) & $651(89.5)$ & $653(89.8)$ & 0.9 \\
\hline \multicolumn{4}{|l|}{ Year } \\
\hline $2011, \mathrm{n}(\%)$ & $52(7.2)$ & $41(5.6)$ & 6.2 \\
\hline $2012, \mathrm{n}(\%)$ & $88(12.1)$ & $84(11.6)$ & 1.7 \\
\hline $2013, \mathrm{n}(\%)$ & $229(31.5)$ & $228(31.4)$ & 0.3 \\
\hline $2014, \mathrm{n}(\%)$ & $358(49.2)$ & $374(51.4)$ & 4.4 \\
\hline \multicolumn{4}{|c|}{$\begin{array}{l}\text { Values are presented as means (SDs) if normally distributed, median (IQR) if non-normally distributed numerical variables, and N (\%) i } \\
\text { categorical variables. } \\
\text { Body mass index was calculated as weight in kilograms divided by the square of height in meters. } \\
\text { Abbreviations: } \mathrm{CR} \text {, cardiac rehabilitation; SD, standard deviation; IQR, interquartile range; ADL, activities of daily living; ICU, intensive } \\
\text { care unit; CCU, coronary care unit; IABP, intra-aortic balloon pumping; ACE, angiotensin-converting enzyme; ARB, angiotensin recepto } \\
\text { blockers. }\end{array}$} \\
\hline
\end{tabular}


Supplemental Table 4 Baseline characteristics of the imputed and matched cohort (2/20)

\begin{tabular}{|c|c|c|c|}
\hline & CR group, $\mathrm{n}=727$ & No CR group, $n=727$ & Standardized difference, $\%$ \\
\hline \multicolumn{4}{|l|}{ Clinical characteristics } \\
\hline Age, years, mean (SD) & $65.1(11.0)$ & $65.5(12.3)$ & 3.3 \\
\hline Male sex, n (\%) & $586(80.6)$ & $594(81.7)$ & 2.8 \\
\hline Body mass index, mean (SD) & $24.4(3.7)$ & $24.2(3.5)$ & 6.6 \\
\hline Smoking history, n (\%) & $407(56.0)$ & $412(56.7)$ & 1.4 \\
\hline \multicolumn{4}{|l|}{ Killip class, n (\%) } \\
\hline 1 & $394(54.2)$ & $401(55.2)$ & 1.9 \\
\hline 2 & $231(31.8)$ & $222(30.5)$ & 2.7 \\
\hline 3 & $48(6.6)$ & $51(7.0)$ & 1.6 \\
\hline 4 & $54(7.4)$ & $53(7.3)$ & 0.5 \\
\hline \multicolumn{4}{|l|}{ Infarction site } \\
\hline Anterior, n (\%) & $359(49.4)$ & $349(48.0)$ & 2.8 \\
\hline Inferior, $\mathrm{n}(\%)$ & $271(37.3)$ & $270(37.1)$ & 0.3 \\
\hline Other, n (\%) & $97(13.3)$ & $108(14.9)$ & 4.3 \\
\hline Ambulance use, $\mathrm{n}(\%)$ & $425(58.5)$ & $427(58.7)$ & 0.6 \\
\hline \multicolumn{4}{|l|}{ Comorbidities } \\
\hline Peripheral vascular disease, $\mathrm{n}(\%)$ & $43(5.9)$ & $43(5.9)$ & 0 \\
\hline Cerebral artery disease, $\mathrm{n}(\%)$ & $33(4.5)$ & $28(3.9)$ & 3.4 \\
\hline Chronic pulmonary disease, $\mathrm{n}(\%)$ & $25(3.4)$ & $14(1.9)$ & 9.4 \\
\hline Liver disease, $\mathrm{n}(\%)$ & $23(3.2)$ & $28(3.9)$ & 3.7 \\
\hline Diabetes mellitus, n (\%) & $261(35.9)$ & $254(34.9)$ & 2 \\
\hline Renal disease, $\mathrm{n}(\%)$ & $16(2.2)$ & $18(2.5)$ & 1.8 \\
\hline Malignant neoplasms, n (\%) & $18(2.5)$ & $14(1.9)$ & 3.8 \\
\hline Low-ADL at discharge, $\mathrm{n}(\%)$ & $34(4.7)$ & $29(4.0)$ & 3.4 \\
\hline \multicolumn{4}{|l|}{ Procedural characteristics } \\
\hline Drug-eluting stent, $\mathrm{n}(\%)$ & $496(68.2)$ & $500(68.8)$ & 1.2 \\
\hline Bare-metal stent, n (\%) & $234(32.2)$ & $241(33.1)$ & 2.1 \\
\hline \multicolumn{4}{|l|}{ Number of coronary stents, $\mathrm{n}(\%)$} \\
\hline 1 & $369(50.8)$ & $383(52.7)$ & 3.9 \\
\hline 2 & $155(21.3)$ & $148(20.4)$ & 2.4 \\
\hline 3 & $70(9.6)$ & $81(11.1)$ & 5 \\
\hline$\geq 4$ & $75(10.3)$ & $75(10.3)$ & 0 \\
\hline ICU/CCU admission, n (\%) & $627(86.2)$ & $615(84.6)$ & 4.7 \\
\hline Respirator use, $\mathrm{n}(\%)$ & $65(8.9)$ & $75(10.3)$ & 4.7 \\
\hline Hemodialysis, n (\%) & $11(1.5)$ & $11(1.5)$ & 0 \\
\hline IABP use, n (\%) & $106(14.6)$ & $118(16.2)$ & 4.6 \\
\hline Transfusion, n (\%) & $24(3.3)$ & $30(4.1)$ & 4.4 \\
\hline Admission period, days, mean (SD) & $16.6(9.0)$ & $16.6(8.6)$ & 0.3 \\
\hline \multicolumn{4}{|l|}{ Medications } \\
\hline Aspirin, n (\%) & $717(98.6)$ & $717(98.6)$ & 0 \\
\hline P2Y12 inhibitors, n (\%) & $712(97.9)$ & $709(97.5)$ & 2.8 \\
\hline Oral anticoagulants, $\mathrm{n}(\%)$ & $121(16.6)$ & $121(16.6)$ & 0 \\
\hline ACE inhibitors/ARBs, n (\%) & $591(81.3)$ & $577(79.4)$ & 4.8 \\
\hline Beta blockers, n (\%) & $523(71.9)$ & $526(72.4)$ & 0.9 \\
\hline Statins, n (\%) & $661(90.9)$ & $654(90.0)$ & 3.3 \\
\hline Catecholamine, n (\%) & $184(25.3)$ & $189(26.0)$ & 1.6 \\
\hline \multicolumn{4}{|l|}{ Hospital characteristics } \\
\hline Number of beds, $\geq 500, \mathrm{n}(\%)$ & $231(31.8)$ & $218(30.0)$ & 3.9 \\
\hline Teaching hospital, n (\%) & $651(89.5)$ & $647(89.0)$ & 1.8 \\
\hline \multicolumn{4}{|l|}{ Year } \\
\hline $2011, \mathrm{n}(\%)$ & $52(7.2)$ & $57(7.8)$ & 2.6 \\
\hline $2012, \mathrm{n}(\%)$ & $88(12.1)$ & $84(11.6)$ & 1.7 \\
\hline $2013, \mathrm{n}(\%)$ & $229(31.5)$ & $237(32.6)$ & 2.4 \\
\hline $2014, \mathrm{n}(\%)$ & $358(49.2)$ & $349(48.0)$ & 2.5 \\
\hline \multicolumn{4}{|c|}{$\begin{array}{l}\text { Values are presented as means (SDs) if normally distributed, median (IQR) if non-normally distributed numerical variables, and N (\%) i } \\
\text { categorical variables. } \\
\text { Body mass index was calculated as weight in kilograms divided by the square of height in meters. } \\
\text { Abbreviations: CR, cardiac rehabilitation; SD, standard deviation; IQR, interquartile range; ADL, activities of daily living; ICU, intensive } \\
\text { care unit; CCU, coronary care unit; IABP, intra-aortic balloon pumping; ACE, angiotensin-converting enzyme; ARB, angiotensin receptor } \\
\text { blockers. }\end{array}$} \\
\hline
\end{tabular}


Supplemental Table 5 Baseline characteristics of the imputed and matched cohort (3/20)

\begin{tabular}{|c|c|c|c|}
\hline & CR group, $\mathrm{n}=727$ & No CR group, $\mathrm{n}=727$ & Standardized difference, \% \\
\hline \multicolumn{4}{|l|}{ Clinical characteristics } \\
\hline Age, years, mean (SD) & $65.1(11.0)$ & $65.0(12.6)$ & 0.7 \\
\hline Male sex, n (\%) & $586(80.6)$ & $578(79.5)$ & 2.8 \\
\hline Body mass index, mean (SD) & $24.5(3.7)$ & $24.3(4.0)$ & 4.1 \\
\hline Smoking history, n (\%) & $409(56.3)$ & $396(54.5)$ & 3.6 \\
\hline \multicolumn{4}{|l|}{ Killip class, n (\%) } \\
\hline 1 & $397(54.6)$ & $415(57.1)$ & 5 \\
\hline 2 & $227(31.2)$ & $233(32.0)$ & 1.8 \\
\hline 3 & $50(6.9)$ & $37(5.1)$ & 7.5 \\
\hline 4 & $53(7.3)$ & $42(5.8)$ & 6.1 \\
\hline \multicolumn{4}{|l|}{ Infarction site } \\
\hline Anterior, n (\%) & $353(48.6)$ & $357(49.1)$ & 1.1 \\
\hline Inferior, n (\%) & $278(38.2)$ & $283(38.9)$ & 1.4 \\
\hline Other, n (\%) & $96(13.2)$ & $87(12.0)$ & 3.7 \\
\hline Ambulance use, $\mathrm{n}(\%)$ & $425(58.5)$ & $456(62.7)$ & 8.7 \\
\hline \multicolumn{4}{|l|}{ Comorbidities } \\
\hline Peripheral vascular disease, $\mathrm{n}(\%)$ & $43(5.9)$ & $45(6.2)$ & 1.2 \\
\hline Cerebral artery disease, $\mathrm{n}(\%)$ & $33(4.5)$ & $36(5.0)$ & 1.9 \\
\hline Chronic pulmonary disease, $\mathrm{n}(\%)$ & $25(3.4)$ & $34(4.7)$ & 6.3 \\
\hline Liver disease, $\mathrm{n}(\%)$ & $23(3.2)$ & $21(2.9)$ & 1.6 \\
\hline Diabetes mellitus, n (\%) & $261(35.9)$ & $255(35.1)$ & 1.7 \\
\hline Renal disease, n (\%) & $16(2.2)$ & $17(2.3)$ & 0.9 \\
\hline Malignant neoplasms, n (\%) & $18(2.5)$ & $18(2.5)$ & 0 \\
\hline Low-ADL at discharge, $\mathrm{n}(\%)$ & $35(4.8)$ & $33(4.5)$ & 1.3 \\
\hline \multicolumn{4}{|l|}{ Procedural characteristics } \\
\hline Drug-eluting stent, n (\%) & $496(68.2)$ & $507(69.7)$ & 3.3 \\
\hline Bare-metal stent, n (\%) & $234(32.2)$ & $221(30.4)$ & 3.9 \\
\hline Number of coronary stents, n (\%) & . & . & \\
\hline 1 & $369(50.8)$ & $414(56.9)$ & 12 \\
\hline 2 & $155(21.3)$ & $141(19.4)$ & 4.8 \\
\hline 3 & $70(9.6)$ & $63(8.7)$ & 3.3 \\
\hline$\geq 4$ & $75(10.3)$ & $72(9.9)$ & 1.4 \\
\hline ICU/CCU admission, n (\%) & $627(86.2)$ & $635(87.3)$ & 3.3 \\
\hline Respirator use, $\mathrm{n}(\%)$ & $65(8.9)$ & $52(7.2)$ & 6.6 \\
\hline Hemodialysis, n (\%) & $11(1.5)$ & $11(1.5)$ & 0 \\
\hline IABP use, n (\%) & $106(14.6)$ & $96(13.2)$ & 4 \\
\hline Transfusion, $\mathrm{n}(\%)$ & $24(3.3)$ & $28(3.9)$ & 3 \\
\hline Admission period, days, mean (SD) & $16.6(9.0)$ & $16.4(9.6)$ & 1.4 \\
\hline \multicolumn{4}{|l|}{ Medications } \\
\hline Aspirin, n (\%) & $717(98.6)$ & $713(98.1)$ & 4.3 \\
\hline P2Y12 inhibitors, n (\%) & $712(97.9)$ & $710(97.7)$ & 1.9 \\
\hline Oral anticoagulants, n (\%) & $121(16.6)$ & $119(16.4)$ & 0.7 \\
\hline ACE inhibitors/ARBs, n (\%) & $591(81.3)$ & $593(81.6)$ & 0.7 \\
\hline Beta blockers, n (\%) & $523(71.9)$ & $506(69.6)$ & 5.1 \\
\hline Statins, n (\%) & $661(90.9)$ & $655(90.1)$ & 2.8 \\
\hline Catecholamine, $\mathrm{n}(\%)$ & $184(25.3)$ & $182(25.0)$ & 0.6 \\
\hline \multicolumn{4}{|l|}{ Hospital characteristics } \\
\hline Number of beds, $\geq 500, \mathrm{n}(\%)$ & $231(31.8)$ & $202(27.8)$ & 8.7 \\
\hline Teaching hospital, n (\%) & $651(89.5)$ & $646(88.9)$ & 2.2 \\
\hline Year & . & . & \\
\hline $2011, \mathrm{n}(\%)$ & $52(7.2)$ & $64(8.8)$ & 6.1 \\
\hline $2012, \mathrm{n}(\%)$ & $88(12.1)$ & $87(12.0)$ & 0.4 \\
\hline 2013, n (\%) & $229(31.5)$ & $224(30.8)$ & 1.5 \\
\hline $2014, \mathrm{n}(\%)$ & $358(49.2)$ & $352(48.4)$ & 1.7 \\
\hline \multicolumn{4}{|c|}{$\begin{array}{l}\text { Values are presented as mean }(\mathrm{SD}) \text { if normally distributed, median }(\mathrm{IQR}) \text { if non-normally distributed numerical variables, and } \mathrm{N}(\%) \mathrm{i} \\
\text { categorical variables. } \\
\text { Body mass index was calculated as weight in kilograms divided by the square of height in meters. } \\
\text { Abbreviations: } \mathrm{CR} \text {, cardiac rehabilitation; } \mathrm{SD} \text {, standard deviation; IQR, interquartile range; } \mathrm{ADL} \text {, activities of daily living; ICU, intensive } \\
\text { care unit; } \mathrm{CCU} \text {, coronary care unit; } \mathrm{ABBP} \text {, intra-aortic balloon pumping; ACE, angiotensin-converting enzyme; ARB, angiotensin recepto } \\
\text { blockers. }\end{array}$} \\
\hline
\end{tabular}

